DOI: 10.26730/1999-4125-2020-2-50-57

УДК 622.272.6

\author{
ИССЛЕДОВАНИЕ И РАЗРАБОТКА СПОСОБОВ ЛИКВИДАЦИИ \\ АВАРИЙНЫХ УЧАСТКОВ ТРУБОПРОВОДА ДЛЯ ТРАНСПОРТИРОВКИ \\ ЗАКЛАДОЧНОЙ СМЕСИ НА РУДНИКАХ ТАЛНАХСКОГО \\ МЕСТОРОЖДЕНИЯ
}

\title{
RESEARCH AND DEVELOPMENT OF MITIGATION METHODS FOR EMERGENCY SECTIONS OF STOWING TRANSPORTATION PIPELINE AT THE MINES OF THE TALNAKH DEPOSIT
}

Бритвин Денис Сергеевич, аспирант. e-mail:Baumann.Q@yandex.ru

Denis S. Britvin, postgraduate Алексеев Роман Радионович, аспирант, e-mail:lager92@mail.ru Roman R. Alekseev, postgraduate Волков Евгений Павлович, старший преподаватель. e-mail:volkoff2@yandex.ru, Eugene P. Volkov, senior lecturer Ахпашев Богдан Андреевич, канд. техн. наук, доцент. e-mail:79050863461@yandex.ru, Bogdan A. Akhpashev, Candidate of technical sciences, Associate Professor

Сибирский федеральный университет», Институт горного дела, геологии и геотехнологий, просп. Красноярский рабочий, 95, г. Красноярск, 660095, Россия. Siberian Federal University, Institute of Mining, Geology and Geotechnologies, 95, Krasnoyarskiy Rabochiy Avenue, Krasnoyarsk, 660095, Russia.

\section{Аннотация:}

Исследование и анализ направлены на изучение проблем, возникаюших при транспортировке закладочных смесей по трубопроводным магистралям от закладочного комплекса до выработанного пространства, на поиск решения сокращения времени простоя при аварийных работах, определения возможности повторного использования забутованного трубопровода и способа его очистки.

Ключевые слова: литая твердеющая смесь, трубопровод, закладка, подземная разработка, разбутовка.

Abstract:

The research and analysis are aimed at studying the problems arising during transportation of stowing along pipelines from the backfill complex to worked-out area. Finding a solution to reducing downtime during emergency operations, determining the possibility of reusing the stemmed pipe and its clean-up procedure.

Key words: inclined deposits, design, chamber system of development, laying, underground development, development.

1. Введение

При выемке рудных залежей на больших глубинах распространение получили системы разработки с закладкой. Системы разработки с закладкой выработанного пространства используются при отработке залежей сложной формы с ценными рудами, при залегании рудных тел под производственными и социальными объектами. Опыт закладки выработанного пространства показывает, что наиболее распространенной технологией заполнения отработанных пустот является применение литой твердеющей смеси (далее ЛТС). Основное достоинство ЛТС является управление горным 


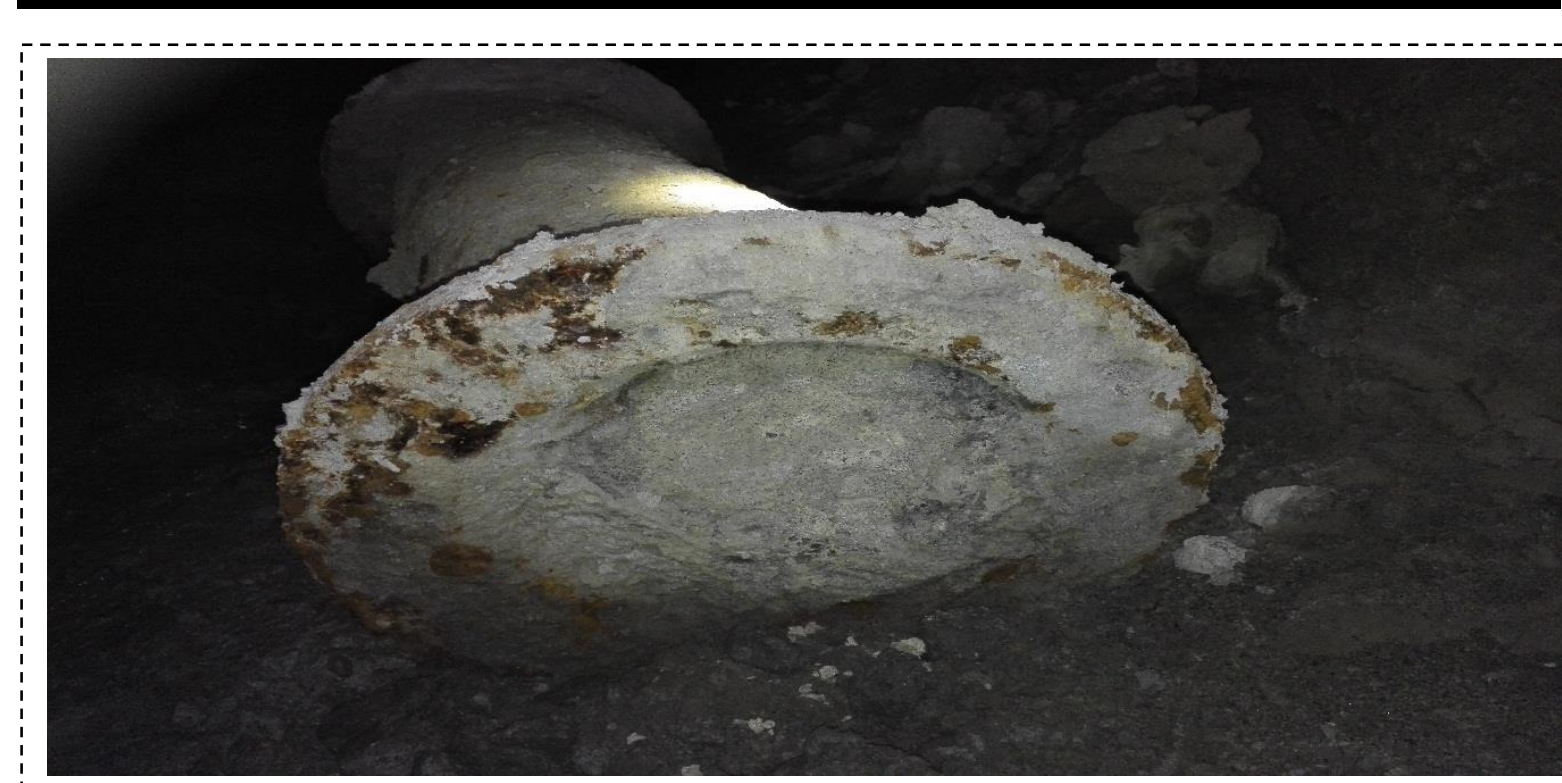

Рис. 1. Аварийный участок при порыве бетоновода

Fig. 1. Emergency section of a ruptured concrete delivery pipe

давлением при твердении в выработанном пространстве, мобильность ее доставки, использование в качестве компонентов различных производственных отходов с возможностью их утилизации, снижающих их себестоимость.

Основные проблемы, которые возникают при транспортировке закладочной смеси по трубопроводу:

- износ трубопровода;

- забутовка трубопровода (рис.1).

Причины забутовки:

- случайное попадание (человеческий фактор) в трубопровод промышленного материала (мусор, металл, изношенные части мелющего оборудования);

- большое количество отводов и изменений внутреннего диаметра транспортирующего трубопровода (трубопровод 219мм, скважина 160мм при перепуске с горизонта на горизонт или в закладочную выработку);

- прямолинейные участки трубопроводов, которые имеют маленький угол наклона и большую протяженность.

Забутовка бетоновода приводит к дорогому и трудоемкому ремонту, сопровождающемуся простоем данного направления трубопровода. В масштабах рудника эта проблема выглядит следующим образом: разрыв бетоновода заливает выработанное пространство, при этом направление останавливается на время устранения аварии. Добыча полезного ископаемого прекращается. Это приводит к тому, что приходится немедленно пересматривать места проведения очистных работ, что сопряжено с перераспределением техники на дополнительные подготовительные работы.

Это приводит к тому, что приходится немедленно пересматривать места проведения очистных работ, что сопряжено с перераспределением техники на дополнительные подготовительные работы. В итоге в большинстве случаев это приводит к невыполнению плана по руднику как по добыче, так и по закладке выработанного пространства. На данный момент на рудниках ежегодно закупается новая и высокопроизводительная техника для ведения горных работ. В то же время технология закладки выработанного пространства остается на прежнем уровне и уже не соответствует сложившимся требованиям. Также не стоит забывать, что закладка выработанного пространства является одним из основных видов управления горным давлением, что является очень важным для обеспечения безопасности ведения горных работ. Стоимость закладочных смесей из-за того, что в их состав входит цемент, является высокой. Следовательно, аварийные ситуации создают дополнительные расходы, так как часть закладочных смесей при порыве изливается в горные выработки, для этого не предназначенные, а часть остается в бетоноводе. Также было отмечено, что при порыве трубопровода вся изливающаяся ЛТС, как правило, остается рядом с аварийным участком, и подъезд или подход к поврежденному участку трубопровода весьма затруднен. К ремонтным работам приступить представляется возможным только после полной зачистки выработки от ЛТС, в которой произошел порыв трубопровода. Необходимо учитывать, что сроки твердения готовых смесей такие же, как в аварийном трубопроводе, протяженность всех закладочных трубопроводов составляет десятки километров, большинство магистральных трубопроводов проходит по старым выработкам (более 20 лет), и постоянно изменяющееся горное давление влияет на их форму. Существует очень много труднодоступных выработок, зачистка которых подземной-доставочной машиной (далее ПДМ) невозможна. Как правило, если зачистку 
Вестник Кузбасского государственного технического университета. 2020. № 2, с.50-57

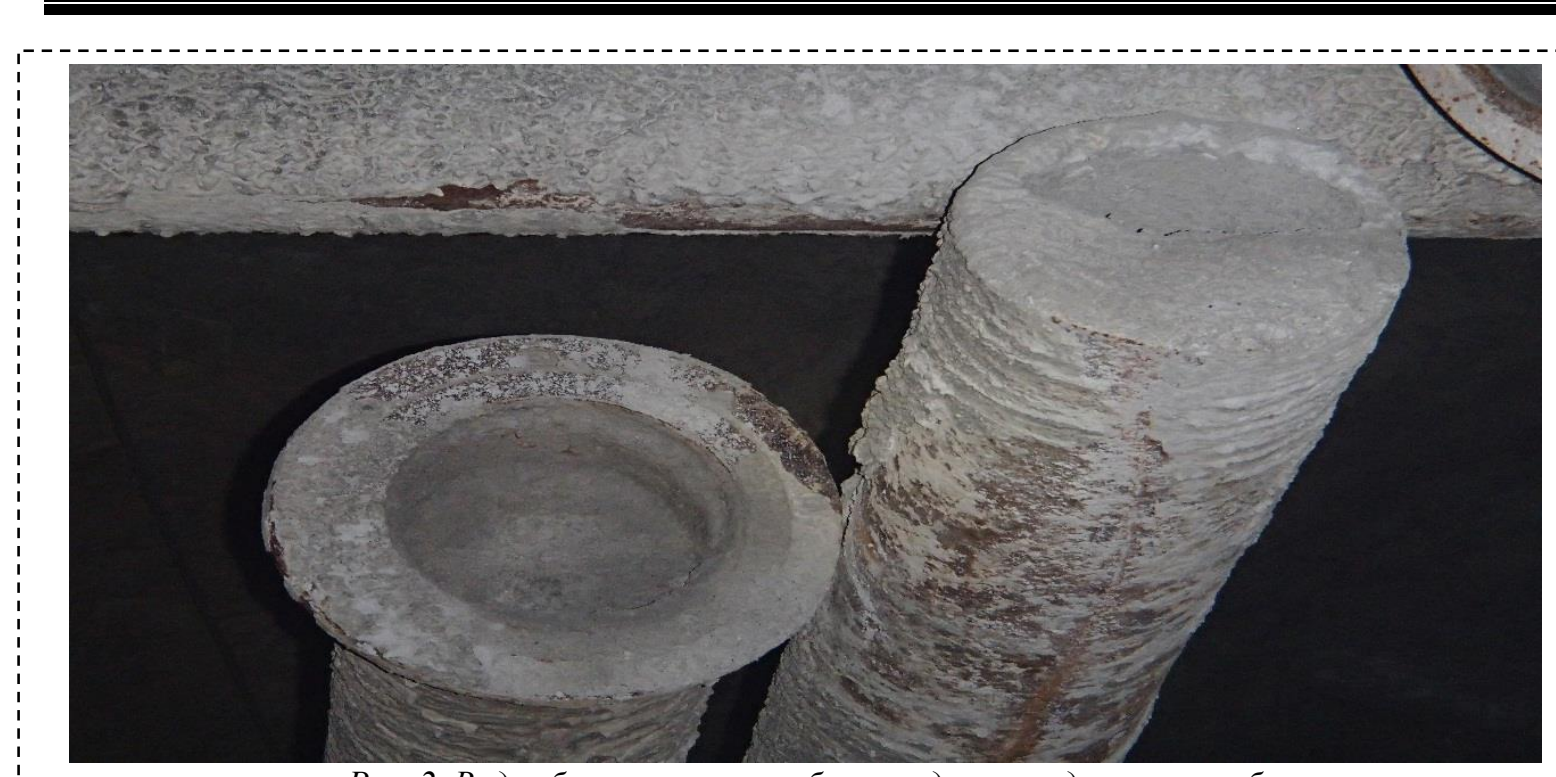

Рис. 2. Вид забутованного трубопровода на соединении труб

Fig. 2. View of the stemmed pipeline at pipe connection

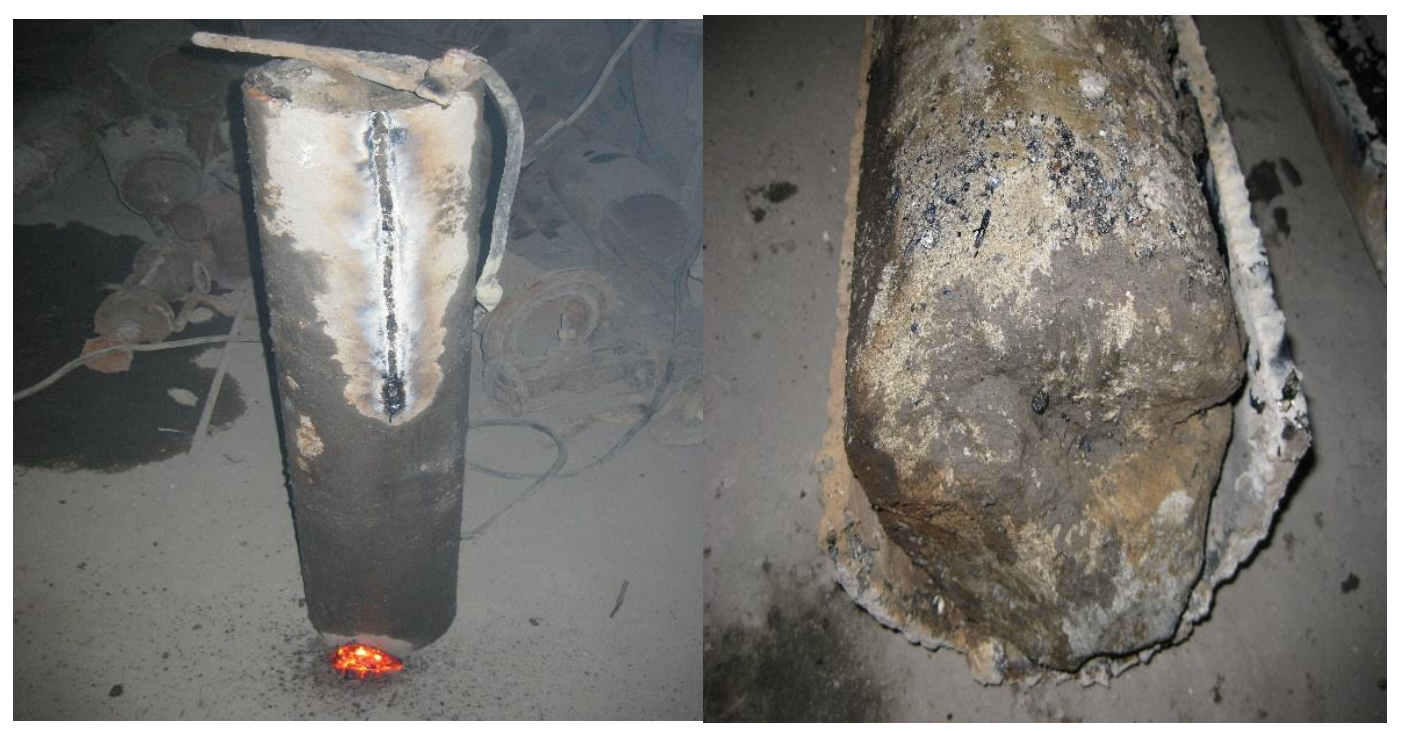

Рис. 3,4. Разрез забутованного участка трубопровода

Fig. 3.4. Section of the stemmed pipeline section

выработки произвести при помощи ПДМ невозможно, то монтируется новая трубопроводная магистраль в обход аварийного участка, что сопряжено с большими расходами на подготовительные работы.

Устаревшая технология закладки не успевает за проходкой. Учитывая аварийные ситуации (забутовка, порыв бетоновода), это является сдерживающим фактором выполнения плана горных работ.

Создание технологии очистки забутованных трубопроводов и технологии очистки аварийного участка от излившейся ЛТС с экономической точки зрения важны и необходимы.

Целесообразное решение описанных проблем - в создании бурового оборудования для эффективной разбутовки трубопровода. Процесс создания бурового оборудования сопряжен с необходимостью получения первоначальных исследования характеристик ЛТС и аварийного трубопровода [1-4].

\section{2. Исследование}

1.Исследование мест хранения и складирования аварийных участков закладочного трубопровода.

Основные места хранения закладочного трубопровода - расстрелы под кровлей (рис. 2), по которым уложен действующий трубопровод, и борта выработок в непосредственной близости. Данные условия диктуются трудоемким и опасным процессом демонтажа с привлечением самоходной техники и ремонтного персонала. Необходимо учитывать, что вес трубопровода с затвердевшей литой закладочной смесью многократно больше.

Складирование на расстрелах позволяет сократить время, необходимое на восстановление работоспособности действующего трубопровода. 

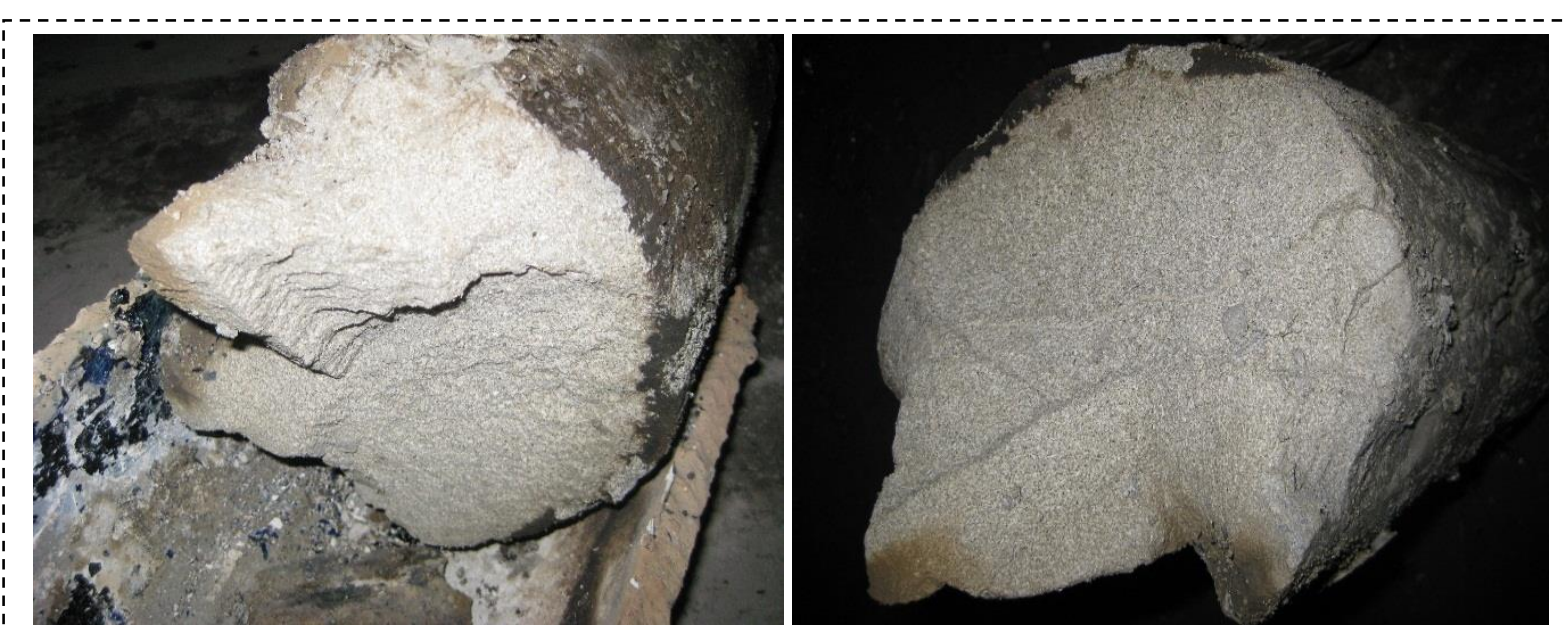

Рис. 5, 6. Структура ЛТС аварийного участка трубопровода

Fig. 5, 6. Structure of the cast hardening material (CHM) at the emergency pipeline section

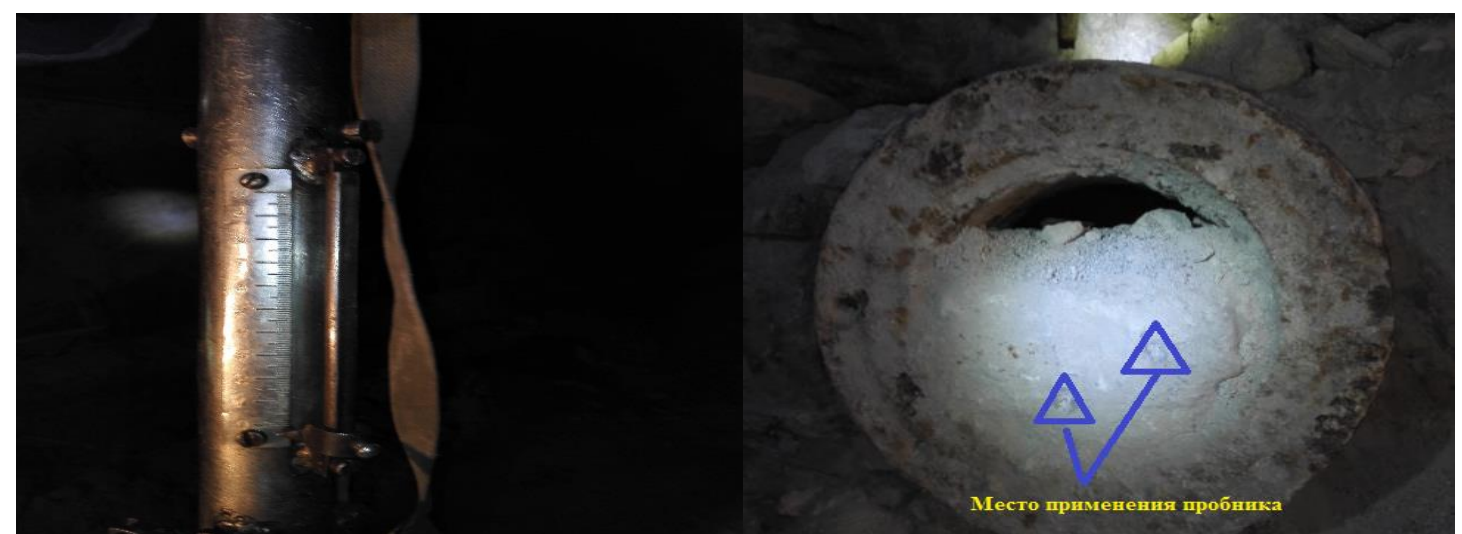

Рис. 7, 8. Шкала пробника П-1, исследование прочности ЛТС забутованного участка трубопровода Fig. 7, 8. Scale of the P-1 probe, strength study of CHM of the stemmed section of the pipeline

Данный процесс начинается с расстыковки аварийного участка по фланцам или сварному соединению. Забутованный трубопровод смещается в сторону, освобождая необходимое пространство, для монтажа нового участка трубы. Смещение в сторону возможно только при наличии свободных мест на расстрелах. При недостатке мест производится демонтаж забутованного трубопровода на почву с дальнейшим его складированием у бортов выработки с сохранением достаточного места для передвижения самоходной техники и людей. В настоящее время данным трубопроводам не находят применения. Внешний и внутренний осмотр забутованного трубопровода, простукивание стенок позволяют сделать вывод, что эксплуатационные характеристики трубы соответствуют техническим условиям. Проведение подготовительных работ (разбутовка) дает перспективу их последующей эксплуатации.

2.Исследование участка закладочного трубопровода путем разложения на отдельные составляющие части.

Для данного исследования был выбран участок аварийного трубопровода горизонта -450 метр, на котором произошла забутовка сроком 10 дней, выработка горизонтальная, протяженностью более 500 метров. Для исследования данный горизонт был выбран вследствие большого количества аварий, происходящих на нем по отношению к другим горизонтам. При помощи дуговой сварки вдоль забутованного трубопровода (рис. 3,4) было выполнено два параллельных разреза, задача состояла в отделении одной части трубы для исследования литой твердеющей смеси внутри трубы. Задача исследования состояла в следующем:

- определить последовательность затвердевания ЛТС;

определить заполнение внутреннего пространства трубы ЛТС;

- по возможности определить прочность ЛТС;

- определить структуру ЛТС;

- определить внутреннее состояние трубы.

Демонтаж одной половины трубы показал, что ЛТС заполнила весь внутренний объем трубы. Разделив ЛТС на отдельные части, производился осмотр на предмет последовательности застывания. Структура была однородная, мелкозернистая, процесс застывания проходил одновременно по всему сечению трубы, следов образования пластов или напластования 
Вестник Кузбасского государственного технического университета. 2020. № 2, с.50-57

Таблица. Показатели прочности ЛТС в забутованных трубах

Table. CHM durability indices in stemmed pipes

\begin{tabular}{|c|c|c|}
\hline Номер образца & $\begin{array}{c}\text { Глубина проникновение иглы динамического } \\
\text { пробника, мм }\end{array}$ & $\begin{array}{c}\text { Прочность образца, } \\
\text { МПа }\end{array}$ \\
\hline 1 & $17 ; 15 ; 17 ; 15$ & 1.8 \\
\hline 2 & $5 ; 4$ & 9.7 \\
\hline 3 & $24 ; 40 ; 37$ & 0.4 \\
\hline 4 & $27 ; 7 ; 5 ; 20$ & 2.1 \\
\hline 5 & $36 ; 66$ & 0.4 \\
\hline 6 & $7 ; 7$ & 7 \\
\hline 7 & $13 ; 14$ & 2.5 \\
\hline 8 & $5 ; 3$ & 9.7 \\
\hline 9 & $12 ; 5$ & 3.5 \\
\hline 10 & $10 ; 10$ & \\
\hline
\end{tabular}

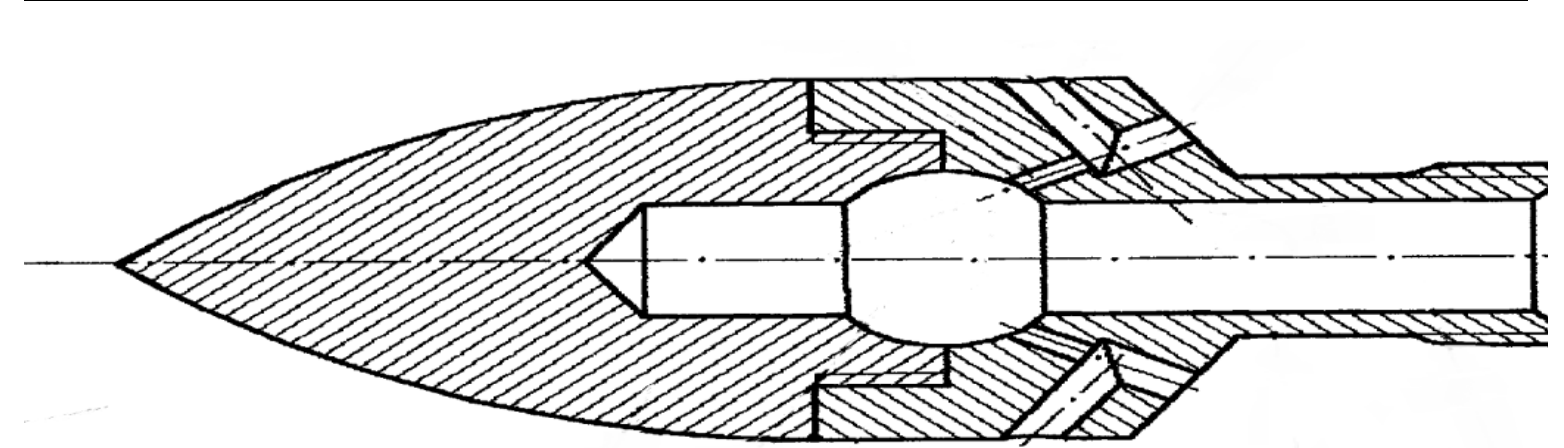

Pис. 9. Форсунка

Fig. 9. Nozzle

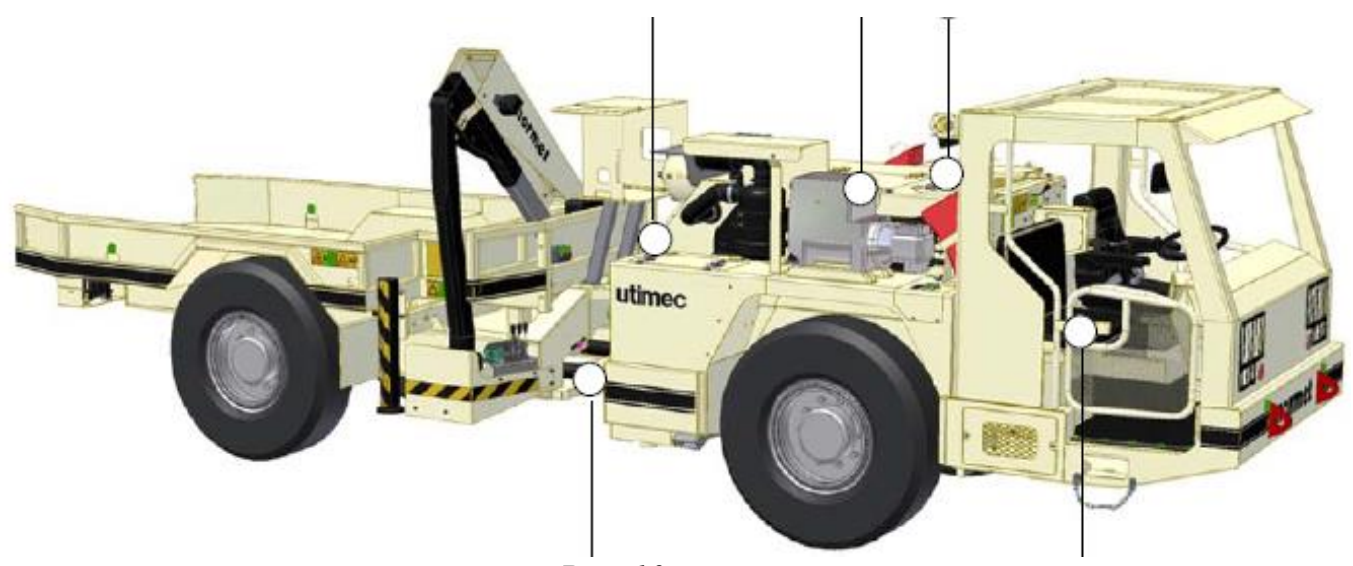

Puc. 10. Normet

Fig. 10. Normet

обнаружено не было (рис. 5,6).

Прочность ЛТС была низкой, при воздействии руки местами поддавалась разрушению в виде откалывания кусков.

Процесс создания бурового оборудования сопряжен с необходимостью получения первоначальных исследований ЛТС.

3. Экспресс-методом при помощи динамического пробника П-1 конструкции ИГД имени А.А. Скочинского определяем фактическую прочность забутованных труб (рис. 7,8).

Основные места хранения - расстрелы под кровлей, по которым уложен действующий трубопровод, и борта выработок в непосредственной близости.

Образцами для измерения прочности 


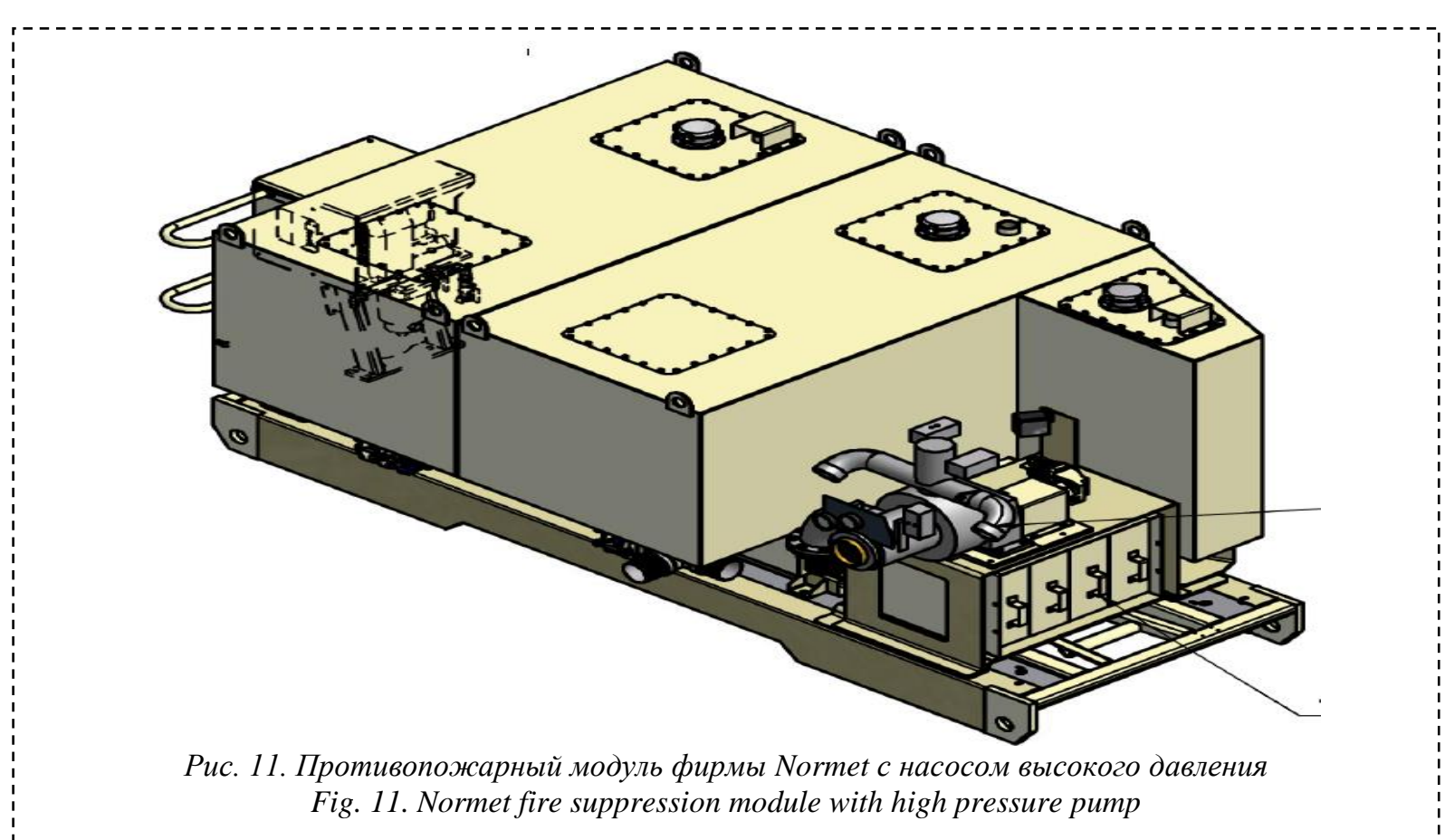

выбирались как демонтированные участки при помощи сварки, так и участки, которые остались на расстрелах.

Из проведенных исследований были отобраны 10 образцов, на основании которых делается заключение о необходимых параметрах бурового оборудования [5-10].

Показания прочности до 3.5 МПа принадлежат закладочной смеси состава АШЩЦ М30, свыше 3.5 МПа АШЦ М100.

\section{3. Вывод}

На основании полученных результатов видится актуальным подбор методов разрушения закладочной смеси в забутованном трубопроводе. Перспективными представляются гидродинамические машины каналопромывочными форсунками (рис. 9).

Для транспортировки к аварийным участкам трубопровода оборудования для промывки закладочных труб целесообразно применять машины типа Normet (рис. 10), которые получили широкое применение в современной горной промышленности.
Возможность установки на шасси Normet пожарного модуля (рис. 11) с общим объемом воды 4400 литров, насосом высокого давления для подачи на форсунку необходимого давления повышает мобильность и снижает зависимость от использования длинных шлангов для подключения воды от противопожарного трубопровода.

Результаты описанных исследований аварийных участков трубопровода подтверждают предположения повторного использования трубопровода после разбутовки. Следовательно, подтверждается уменьшение затрат на приобретение новой бетоноводной трубы, времени на проведения замены аварийного участка.

Например, расстыковка аварийного участка от действующего става, разбутовка его по месту при помощи бурового оборудования, монтаж в исходно действующий став. Данный вид ремонта будет существенно сокращать простои при закладке подземных горных выработок [10-16].

\section{СПИСОК ЛИТЕРАТУРЫ}

1. Каплунов Д.Р., Юков В.А. Энергосбережение в процессах подземной добычи медных руд. Горный информационно-аналитический бюллетень (научно-технический журнал). - 2016. -№4. - С. 5-17.

2. Анушенков А.Н. Разработка комплексов приготовления и транспорта твердеющих смесей для закладки горных выработок. Красноярск: ГУЦМиЗ, 2006. - 170 с.

3. Анушенков А.Н., Стовманенко А.Ю., Волков Е.П. «Основы процессов производства и транспортирования закладочных смесей при подземной разработке месторождений полезных ископаемых: учеб. пособие - Красноярск, СФУ, 2015. - 208 с.

4. Анушенков А.Н. Производство закладочных работ на примере Таштагольского подземного рудника. Красноярск: СФУ, 2016. - 136 с. 
5. Анушенков А.Н., Бритвин Д.С. Актуальность проблем очистки забутованных закладочных трубопроводов в условиях рудника «Октябрьский» // Электронный сборник материалов международной конференции студентов, аспирантов и молодых ученых «Проспект свободный-2016». Подземные горные работы. Красноярск: СФУ, 2016.

6. Анушенков А.Н., Бритвин Д.С. Исследование аварийных участков забутованных закладочных трубопроводов в условиях рудника «Октябрьский» // Электронный сборник материалов международной конференции студентов, аспирантов и молодых ученых «Проспект свободный-2017». Подземные горные работы. Красноярск: СФУ, 2017.

7. Филимонов В.В., Христолюбов Е.А., Еременко А.А. Обоснование технологических решений по модернизации способов разработки рудных тел системами без и с закладкой выработанного пространства на Таштагольском месторождении. Горный информационно-аналитический бюллетень (научнотехнический журнал). - 2018. -№2. - С. 57-65.

8. Голик В.И., Разоренов Ю.И., Каргинов К.Г., Носырев М.Б. Активация вяжущих для твердеющих смесей. Известия высших учебных заведений. Горный журнал. - 2018. - №1. - С. 8-14.

9. Ляшенко В. И., Франчук В.П. Повышение эффективности активации компонентов твердеющей закладочной смеси в установках вибрационного трубопроводного транспорта. Известия высших учебных заведений. Горный журнал. - 2017. - №4. - С. 92-100.

10.Szponder D.K., Trybalski K. The determination of physico-chemical and mineralogical properties of fly ash used in mining industry // 22nd World Mining Congress \& Expo. Istanbul, 2011. Vol. 2. P. 629-639.

11.Rodriguez J.M., Meneses R., Orus R.J. Active vibration control for electric vehicle compliant drivetrains. Industrial Electronics Society, IECON 2013, 39th Annual Conference of the IEEE, 2013, pp. 2590-2595.

12.Guo Yong, Yang Shu Yi, Liu De Shun, Zhang Long Yan, Chen Jian Wen. Impact performance for high frequency hydraulic rock drill drifter with sleeve valve // International Journal of Fluid Machinery and Systems. 2016. Vol. 9. No. 1. P. 39-46.

13.Поветкин В.В., Керимжанова М.Ф., Орлова Е.П., Букаева А.З. Совершенствование оборудования для транспортировки гидросмеси в обогатительном производстве. Горный информационноаналитический бюллетень (научно-технический журнал). - 2018. -№6. - С. 161-169.

14.Ермолович Е.А., Изместьев К.А. Исследование физико-механических свойств горнометаллургических отходов как компонентов твердеющих закладочных смесей//Горный информационноаналитический бюллетень. 2012. № 10. С. 9-15.

15.Вильчинский В.Б., Трофимов А.В., Корейво А.Б., Галаов Р.Б., Марысюк В.П. Обоснование целесообразности применения систем разработки с закладочными смесями на рудниках Талнаха//Цветные металлы. 2014. № 9. С. 23-28.

16.Feng Guang-Ming, Ding Yu, Zhu Hong-Ju, Bai Jian-Biao. Zhogguo kuangye daxue xuebao//Journal of China University of Mining and Technology. 2010. Vol. 39. № 6. P. 813-819.

\section{REFERENCES}

1. Kaplunov D.R., Yukov V.A. Energy saving in copper ores mining operations. Mining informational and analytical bulletin. 2016, No 4, pp. 5-17. [In Russ].

2. Anushenkov A.N. Development of complexes for the preparation and transport of hardening mixtures for laying mines. Krasnoyarsk: GUTSMiZ, 2006. 170 p.

3. Anushenkov AN, Stovmanenko A.Yu., Volkov E.P. "Fundamentals of the production and transportation of filling mixtures for underground mining of minerals: Proc. Manual - Krasnoyarsk, SFU, 2015. 208 p.

4. Anushenkov A.N, Stowing operations using the example of the Tashtagol underground mine. Krasnoyarsk: SFU, 2016. 136 p.

5. Anushenkov A.N., Britvin D.S. The urgency of the problem of cleaning the filled pipelines in the conditions of the Oktyabrsky mine // Electronic collection of materials of the international conference of students, graduate students and young scientists "Prospekt Svobodny-2016". Underground mining. Krasnoyarsk: Siberian Federal University, 2016.

6. Anushenkov A.N., Britvin D.S. Issledovaniye avariynykh uchastkov zabutovannykh zakladnykh truboprovodov v usloviyakh rudnika «Oktyabr'skiy» // Elektronnyy sbornik materialov mezhdunarodnykh konferentsiy studentov, aspirantov i molodykh uchenykh «Prospekt svobodny-2017». Podzemnyye gornyye raboty. Krasnoyarsk: SFU, 2017.

7. Filimonov V.V., Khristolyubov E.A., Eremenko A.A. Substaniation of process solutions on modernization of mining with and without backfilling at Tashtagol deposit. Mining informational and analytical bulletin. 2018, No 2, pp. 59-65. [In Russ].

8. Golik V.I., Razorenov Iu.I., Karginov K.G., Nosyrev M.B. Aktivasion of binders for hardening mixtures. 
Izveatiya vysshikh uchebnykh zavedenii. Gornyi zhurnal. 2018, No 1, pp. 8-14. [In Russ].

9. Liashenko V.I., Franchuk V.P. Hardening stowage mixtures components activation efficiency improvement in vibration pipeline transport plants. Izveatiya vysshikh uchebnykh zavedenii. Gornyi zhurnal. 2017, No 7, pp. 92-100. [In Russ].

10.Szponder D.K., Trybalski K. The determination of physico-chemical and mineralogical properties of fly ash used in mining industry // 22nd World Mining Congress \& Expo. Istanbul, 2011. Vol. 2. pp. 629-639.

11.Rodriguez J.M., Meneses R., Orus R.J. Active vibration control for electric vehicle compliant drivetrains. Industrial Electronics Society, IECON 2013, 39th Annual Conference of the IEEE, 2013, pp. 2590-2595.

12.Guo Yong, Yang Shu Yi, Liu De Shun, Zhang Long Yan, Chen Jian Wen. Impact performance for high frequency hydraulic rock drill drifter with sleeve valve // International Journal of Fluid Machinery and Systems. 2016. Vol. 9. No. 1. pp. 39-46.

13.Povetkin V.V. Kerimzhanova M.F. Orlova Y. P. Bukayeva A.Z. Improvement of equipment for transport of slurry in mineral processing production. Mining informational and analytical bulletin. 2018, No 6, pp. 161-169. [In Russ].

14.Ermolovich E.A., Izmest'ev K.A. Study of the physicomechanical properties of mining and metallurgical wastes as components of hardening filling mixtures //Gornyj informacionno-analiticheskij bjulljuten'. 2012 . № 10. p. 9-15. [In Russ]

15.Vil'chinskij V.B., Trofimov A.V., Korejvo A.B., Galaov R.B., Marysjuk V.P. Rationale for the use of development systems with filling mixtures in the mines of Talnakh //Cvetnye metally. 2014. № 9. p. 23-28. [In Russ]

16.Feng Guang-Ming, Ding Yu, Zhu Hong-Ju, Bai Jian-Biao. Zhogguo kuangye daxue xuebao//Journal of China University of Mining and Technology. 2010. Vol. 39. № 6. P. 813-819.

Поступило в редакцию 22.01.2020

Received 22 January 2020 